\title{
MiR-22 Suppresses BMP7 in the Development of Cirrhosis
}

\author{
Dong Ji Bing Li Qing Shao Fan Li Zhongbin Li Guofeng Chen
}

Liver Fibrosis Diagnosis and Treatment Center, 302 Hospital of PLA, Beijing, China

\section{Key Words}

Cirrhosis • MicroRNAs $\cdot$ miR-22 Carbon tetrachloride $\left(\mathrm{CCl}_{4}\right) \cdot$ Bone morphogenic protein 7 $(\mathrm{BMP7}) \cdot$ Antisense

\begin{abstract}
Background/Aims: New strategies for the prevention and treatment of cirrhosis are urgently needed for improving therapeutic outcome. A role of microRNAs (miRNAs) in the pathogenesis of cirrhosis has been recently acknowledged, whereas the exact involved miRNAs as well as the associated molecular signaling pathways have not been determined. Specifically, the studies on the relationship between miR-22 and bone morphogenic protein 7 (BMP7) in the development of cirrhosis are lacking. Methods: We examined the correlation of the levels of miR-22 and bone morphogenic protein 7 (BMP7) in the liver biopsies from patients with cirrhosis. We examined overexpression or suppression of miR-22 on BMP7 in hepatocytes. We examined the binding of miR-22 to the $3^{\prime}$-UTR of BMP7 mRNA. Finally, in a carbon tetrachloride $\left(\mathrm{CCl}_{4}\right)$-induced cirrhosis model in mice, we gave mice adeno-associated viruses carrying antisense of miR-22, and examined its effects on BMP7 levels and the hallmarks of cirrhosis. Results: The levels of miR-22 and BMP7 in the liver biopsies from patients were strongly and inversely correlated. MiR-22 inhibited BMP7 expression in hepatocytes, through directly binding the 3'-UTR of BMP7 mRNA. Expression of antisense miR-22 significantly attenuated the levels of liver fibrosis, portal hypertension and sodium retention caused by $\mathrm{CCl}_{4^{\prime}}$ possibly through upregulation of BMP7. Conclusions: MiR-22 promotes the development of cirrhosis through BMP7 suppression.

Copyright $(2015$ S. Karger AG, Basel
\end{abstract}

\section{Introduction}

Hepatitis $\mathrm{C}$ virus (HCV) infection has been determined as a major cause of chronic non-A non-B hepatitis [1-4]. More than 200 million people are estimated to be infected worldwide D. Ji and B. Li contribute equally. 
with the highest prevalence in North Africa and South Asia [1-4]. HCV-infected people have a very high risk of future development of hepatic fibrosis, or cirrhosis, which often predisposes to hepatocellular carcinoma (HCC) [1-4]. The pathological processes of hepatic fibrosis include injury-induced chronic inflammation, portal hypertension due to impaired blood flow, and disruption of normal hepatic architecture leading to liver dysfunction [1-4].

Animal models have been widely used for studying the molecular mechanisms underlying the pathogenesis of cirrhosis [5-10]. So far, the most commonly used cirrhosis model in mice is carbon tetrachloride $\left(\mathrm{CCl}_{4}\right)$ intraperitoneal administration, due to its relatively low toxicity to mice and relatively high reproducibility of cirrhosis development [5-10]. The studies on the molecular mechanism underlying the development of cirrhosis have highlighted a pivotal role of molecules regulating epithelial-mesenchymal transition (EMT) [11], including two multifunctional growth factors from transforming growth factor $\beta$ (TGF $\beta$ ) superfamily [12-14], bone morphogenic protein 7 (BMP7) and TGF $\beta 1$. While TGF $\beta 1$ is a well-established pro-fibrotic factor to induce EMT and fibrosis, BMP7 contradicts the effects of TGF $\beta 1$ to reverse EMT and fibrosis [15-19]. Such antagonism has been shown to coordinate the recovery of the injured liver by us [20], and by others [21-25].

Exosomes are small membranous vesicles of diameter ranging from 30 to $100 \mathrm{~nm}$, and can be isolated from various body fluids such as serum, urine, and malignant ascites [2628]. Exosomes contain unique microRNAs (miRNAs), mRNAs and proteins [26-28]. MiRNAs are small RNA species that range from 19 to 25 nucleotides in length, and are frequently dysregulated in cancer and are associated with cancer development and progression [2628]. Recent findings have implicated the involvement of miRNAs in the HCV infection and development of cirrhosis [29-37]. These pilot studies have shown upregulation of a number of miRNAs in the fibrotic liver, which may imply a possible involvement of miRNAs in the pathogenesis of cirrhosis. However, the exact underlying regulatory molecular pathways have not been completely elucidated. Moreover, the studies on a member of miRNAs called miR-22 in liver, and specifically its interaction with BMP7, is very limited [38, 39].

Here, we show that the levels of miR-22 and BMP7 in the liver biopsies strongly and inversely correlated. MiR-22 inhibited BMP7 expression in hepatocytes, through direct binding and inhibition on 3'-UTR of BMP7 mRNA. Expression of antisense of miR-22 significantly attenuated the levels of liver fibrosis, portal hypertension and sodium retention caused by $\mathrm{CCl}_{4}$, possibly through upregulation of BMP7.

\section{Materials and Methods}

\section{Specimens from patients}

A total of 12 biopsies of cirrhosis from patients were used in this study (Table 1). All specimens had been histologically and clinically diagnosed at Liver Fibrosis Diagnosis and Treatment Center, 302 Hospital of PLA from 2010 to 2014. For the use of these clinical materials for research purposes, prior patient's consents and approval from the Institutional Research Ethics Committee were obtained.

\section{Cell culture}

HepG2 is a human hepatocellular carcinoma (HCC) cell line, which was derived from the liver tissue of a 15-year-old Caucasian American male with a well-differentiated hepatocellular carcinoma [40]. These cells are epithelial in morphology, have a modal chromosome number of 55, and are not tumorigenic in nude

Table 1. Gender and age of the patients' sample

\begin{tabular}{lll}
\hline & Total & Age (M+SD) \\
\hline $\mathrm{n}$ & 12 & \\
Gender & & \\
Male & 6 & $43.2 \pm 7.8$ \\
Female & 6 & $42.5 \pm 6.6$ \\
\hline
\end{tabular}




\section{Cellular Physiology Cell Physiol Biochem 2015;36:1026-1036 \begin{tabular}{l|l|l}
\hline DOI: 10.1159/000430276 & C 2015 S. Karger AG, Basel
\end{tabular} and Biochemistry Published online: June 16, $2015 \quad$ www.karger.com/cpb \\ Ji et al.: MiR-22 Suppresses Cirrhosis}

mice [40]. The cells secrete a variety of major plasma proteins, e.g., albumin, transferrin, $\alpha 2$-macroglobulin, a1-antitrypsin, and plasminogen [40]. HepG2 was purchased from American Type Culture Collection (ATCC), and was cultured in Dulbecco's modified Eagle's medium (DMEM, Life Technologies, San Jose, CA, USA) supplemented with $20 \%$ fetal bovine serum (Invitrogen, Carlsbad, CA, USA).

\section{Plasmids and adeno-associated virus (AAV) preparation}

Plasmids were successfully constructed using molecular cloning technology. Target sequences (miR-22 sequence: 5'-aguucuucaguggcaagcuuua-3', miR-22 antisense (as-) sequence: 5' - uaaagcuugccacugaagaacu-3', scramble (scr) sequence: 5'-uuguacuacacaaaaguaaug-3') were inserted into pGL3-Basic vector (Promega, Beijing, China). HepG2 cells were transfected with Lipofectamine 2000 reagent (Invitrogen), according to the manufacturer's instructions.

As-miR-22 and scr were also used to prepare AAV, as has been previously described [41-43]. Briefly, we used a pAAV-CAG-GFP plasmid as a backbone (Clontech, Mountain View, CA, USA), with a packaging plasmid carrying the serotype 8 rep and cap genes and a helper plasmid carrying the adenovirus helper functions (Applied Viromics, LLC. Fremont, CA, USA) to generate AAV in this study. As-miR-22 and scr sequence were cloned using EcoRIII and NheI restriction endonucleases sites in the backbone plasmid. The plasmid also has a GFP reporter. As-miR-22 and scr were connected with GFP with a 2A sequence, which allows for efficient, stoichiometric production of discrete protein products within a single vector through a novel "cleavage" event. Sequencing was performed to confirm the correct orientation of these new plasmids. AAV was prepared by triple transfection of the prepared AAV plasmids, R2C8 (containing AAV2 Rep and AAV8 capsid genes) and plAd5 (containing adenovirus helper genes) into HEK293 cells (ATCC) by Lipofectamine 2000 reagent (Invitrogen). The viruses were purified using $\mathrm{CsCl}$ density centrifugation and then titered by a quantitative densitometric dot-blot assay.

\section{Luciferase-reporter activity assay}

Luciferase-reporters were successfully constructed using molecular cloning technology. Target sequence was inserted into pGL3-Basic vector (Promega) to obtain pGL3-BMP7-3'UTR, which contains the miR-22 binding sequence (BMP7-3'UTR sequence). HepG2-miR-22, or HepG2-scr, or HepG2-as-miR-22 cells were seeded in 24-well plates for 24 hours, after which they were transfected with $1 \mu \mathrm{g}$ of Luciferasereporter plasmids per well using PEI Transfection Reagent. Then luciferase activities were measured using the dual-luciferase reporter gene assay kit (Promega), according to the manufacturer's instructions.

\section{Animal manipulations}

All animal procedures were conducted according to the guidelines for the care and use of laboratory animals approved by 302 Hospital of PLA. Female C57BL/6 mice (Charles River Laboratories, China) of 10 weeks of age were given free access to tap water and pelleted mouse diet. Cirrhosis was induced by $\mathrm{CCl}_{4}$ intraperitoneal administration. Briefly, $\mathrm{CCl}_{4}$ solution of $50 \%(\mathrm{v} / \mathrm{v})$ in paraffin oil (Sigma-Aldrich, St. Louis, MO, USA) was administered at a dose of $2 \mathrm{ml} / \mathrm{kg}$ body weight of the mice, by intraperitoneal injections twice a week for 8 weeks. Each experimental group contained 10 mice. During cirrhosis induction, the mice were provided with $0.3 \mathrm{~g} / \mathrm{l}$ phenobarbital in drinking water to enhance $\mathrm{CCl}_{4}$ hepatotoxicity.

Liver infusion with as-miR-22

Liver infusion with AAV carrying antisense (as) of miR-22 was performed as has been described before $[36,44-46]$. Briefly, the duodenum was exposed to show the common bile duct, after which a microclamp was placed on the common bile duct close to gallbladder. A 31-gauge blunt-ended catheter was then put into the common bile duct through the sphincter of Oddi in the duodenum till the branching of the left and right hepatic duct, which was then clamped with another microclamp to prevent backflow into pancreas and duodenum. The other end of the catheter is connected to a micro-infusion apparatus, which delivers $200 \mu \mathrm{l}$ of AAV containing $10^{10} \mathrm{AAV}$-as-miR22 viral particles, or control AAV-scrambled viral particles, via the catheter at a rate of $5 \mu \mathrm{l} / \mathrm{min}$. After infusion, the hole created by the catheter in the duodenum was closed with 6-0 gauge suture.

\section{Evaluation of liver fibrosis}

Liver samples were fixed in $10 \%$ phosphate-buffered formalin, embedded in paraffin, and stained with the Sirius red staining technique, which stains collagen. Fibrotic areas were counted on 200 random selected

\section{KARGER}




\section{Cellular Physiology Cell Physiol Biochem 2015;36:1026-1036 \begin{tabular}{ll|l} 
aOI: 10.1159/000430276 & $\begin{array}{l}\text { O 2015 S. Karger AG, Basel } \\
\text { www.karger.com/cpb }\end{array}$ \\
\hline
\end{tabular} \\ Ji et al.: MiR-22 Suppresses Cirrhosis}

fields corresponding to approximately $6 \mathrm{~mm}^{2}$, using an unbiased counting frame, as has been described previously [14]. The percentage of fibrotic area was expressed as number of fibrotic fields divided by total fields, and then multiplied by 100 .

\section{Sodium balance}

The urine sodium concentration (UNa) was assayed by flame photometry (Roika 2000, Roika, UK), and renal sodium excretion ( $\mathrm{UNaV}$ ) was calculated with the following formula: $\mathrm{UNaV}=\mathrm{UV} \times \mathrm{UNa}$, where $\mathrm{UV}$ is urine volume. The intake of sodium was assessed by measuring the amounts of food and water consumed. Sodium balance was calculated as ( $\mathrm{Na}+$ provided by food and water)-UNaV.

\section{Portal pressure}

After evaluation of sodium metabolism, under anesthesia, a PE-50 polyvinyl catheter was placed in the cecal vein. The other end of the catheter was connected to a highly sensitive transducer (ADInstruments Shanghai Trading Co. Shanghai, China) to assess portal pressure.

\section{Quantitative real-time PCR (RT- $q P C R$ )}

miRNAs and total RNAs were extracted from liver specimen or cultured cells with miRNeasy mini kit or RNeasy kit (Qiagen, Hilden, Germany), respectively for cDNA synthesis. No fluid miRNAs were analyzed. Quantitative real-time PCR (RT-qPCR) was performed in duplicates with QuantiTect SYBR Green PCR Kit (Qiagen). All primers were purchased from Qiagen. Data were collected and analyzed with the Rotorgene software accompanying the PCR machine, using 2- $\Delta \Delta \mathrm{Ct}$ method for quantification of the relative mRNA expression levels. Values of genes were first normalized against $\alpha$-tubulin, and then compared to controls to get relative values.

\section{ELISA}

The concentration of BMP7 in the cells and conditioned media was determined by BMP7 ELISA Kit (R\&D System, Los Angeles, CA, USA). ELISA was performed according to the instructions of the manufacturer. Briefly, the collected condition media was added to a well coated with primary antibody against BMP7, and then immunosorbented by biotinylated anti-BMP7 antibody at room temperature for 2 hours. The color development catalyzed by horseradish peroxidase was terminated with $2.5 \mathrm{~mol} / \mathrm{l}$ sulfuric acid and the absorption was measured at $450 \mathrm{~nm}$. The protein concentration was determined by comparing the relative absorbance of the samples with the standards.

\section{Western blot}

Protein was extracted from the mouse liver with RIPA lysis buffer (1\% NP40, 0.1\% Sodium dodecyl sulfate (SDS), $100 \mu \mathrm{g} / \mathrm{ml}$ phenylmethylsulfonyl fluoride, $0.5 \%$ sodium deoxycholate, in PBS) on ice. The supernatants were collected after centrifugation at $12000 \times \mathrm{g}$ at $4^{\circ} \mathrm{C}$ for $20 \mathrm{~min}$. Protein concentration was determined using a BCA protein assay kit (Bio-rad, China), and whole lysates were mixed with $4 \times$ SDS loading buffer (125mmol/l Tris-HCl, 4\% SDS, $20 \%$ glycerol, $100 \mathrm{mmol} / \mathrm{l}$ Dithiothreitol (DTT), and $0.2 \%$ bromophenol blue) at a ratio of $1: 3$. Samples were heated at $100^{\circ} \mathrm{C}$ for $5 \mathrm{~min}$ and were separated on SDSpolyacrylamide gels. The separated proteins were then transferred to a PVDF membrane. The membrane blots were first probed with a primary antibody. After incubation with horseradish peroxidase-conjugated second antibody, autoradiograms were prepared using the enhanced chemiluminescent system to visualize the protein antigen. The signals were recorded using X-ray film. Primary antibodies were rabbit anti-BMP7 and anti- $\alpha$-tubulin (Cell Signaling, San Jose, CA, USA). Secondary antibody is HRP-conjugated anti-rabbit (Jackson ImmunoResearch Labs, West Grove, PA, USA). $\alpha$-tubulin was used as protein loading controls. The protein levels were first normalized to $\alpha$-tubulin, and then normalized to control.

\section{Statistical analysis}

Statistical analyses were performed with SPSS 19.0 software (SSPS Inc., Chicago, IL, USA). All data were statistically analyzed using one-way ANOVA with a Bonferoni correction, followed by Fisher's Exact Test for comparison of two groups. All values are depicted as mean \pm standard deviation, and are considered significant if $\mathrm{p}<0.05$. Each group contained 10 individuals. Bivariate correlations were calculated by Spearman's $r$.

\section{KARGER}




\begin{tabular}{|c|c|c|}
\hline Cellular Physiology & Cell Physiol Biochem 2015;36:1026-1036 & \\
\hline and Biochemistry & $\begin{array}{l}\text { Dor: 10.1159/000430276 } \\
\text { Published online: June 16, } 2015\end{array}$ & $\begin{array}{l}\text { O } 2015 \text { S. Karger AG, Basel } \\
\text { www.karger.com/cpb }\end{array}$ \\
\hline
\end{tabular}

\section{Results}

Levels of miR-22 and BMP7 correlated in the liver biopsies with cirrhosis

BMP7 has a well-established role in suppressing progress of cirrhosis, and recently, a regulatory role of miR-22 on BMP7 has been reported in renal fibrosis [38]. Thus, we were prompted to examine whether miR-22 may play a similar role in cirrhosis. We examined the levels of miR-22 and BMP7 in the liver biopsies from patients with cirrhosis. We detected a strong and inverse correlation between the levels of miR-22 and BMP7 in the liver biopsies (Fig. 1, R=0.80, p<0.001). These data suggest presence of a relationship between miR-22 and BMP in the development of cirrhosis.

MiR-22 suppressed BMP7 expression in hepatocytes

We have recently shown that BMP7 contradicts the effects of TGF $\beta 1$ to reverse EMT and liver fibrosis [20], and BMP7 in liver is predominantly produced by hepatocytes. Thus, we aimed to figure out whether miR-22 may regulate BMP7 expression in hepatocytes. We used a hepatocyte cell line, HepG2, and overexpressed miR-22 or as-miR-22 in these cells. First, modulation of miR-22 levels by AAV transduction in HepG2 cells was confirmed by RT-qPCR (Fig. 2A). We found that the expression of BMP7 in miR-22-overexpressing HepG2 cells was significantly decreased, while the expression of BMP7 in miR-22-depleted HepG2 cells was significantly increased, as measured by RT-qPCR (Fig. 2B), and by ELISA on either cellular protein (Fig. 2C) or secreted protein (Fig. 2D). These data suggest that miR-22 may regulate BMP expression in hepatocytes.

MiR-22 targets $3^{\prime} U T R$ of BMP7 mRNA to inhibit its expression

Since our data suggest that miR-22 may inhibit BMP7 expression, we performed bioinformatics analysis of BMP7 target sequence. Our data suggest that the miR-22 binding sites in the BMP7 mRNA sequence 3'UTR ranged from 129th base site to 159th base site (Fig. 3A). HepG2-miR-22, HepG2-scr (control) and HepG2-as-miR-22 cells were then transfected with $1 \mu \mathrm{g}$ of BMP7-3'UTR Luciferase-reporter plasmid. We found that the luciferase activities in HepG2-as-miR-22 cells were significantly higher than the control scr, while the luciferase activities in HepG2-miR-22 cells were significantly lower than the control scr (Fig. 3B). These data suggest that miR-22 targets 3'UTR of BMP7 mRNA to inhibit its expression.

As-miR-22 significantly alleviated the features of cirrhosis induced by $\mathrm{CCl}_{4}$

In order to evaluate the inhibitory effect of miR-22 on BMP7 and cirrhosis in vivo, we injected $\mathrm{CCl}_{4}$ to induce cirrhosis in mice. Afterwards, the mice received hepatic infusion with AAV that carry as-miR-22, or AAV that carry scr as a control, through common bile duct, and were kept for another 4 weeks before analyses (Fig. 4A).

The rather even infection of whole liver was demonstrated by GFP expression due to the presence of a GFP reporter in both AAV-as-miR-22 and AAV-scr (as a control) (Fig. 4B). The knockdown of miR-22 in liver was confirmed by RT-qPCR on liver samples (Fig. 4C). The

Fig. 1. Levels of miR-22 and BMP7 correlated in the liver biopsies with cirrhosis. We examined the levels of miR-22 and BMP7 in the liver biopsy specimen from patients with different levels of cirrhosis. We detected a strong, and inverse correlation between the levels of miR-22 and BMP7 in the liver biopsies (Fig. 1, R=0.80, p<0.001). Statistics: Spearman's r correlation.

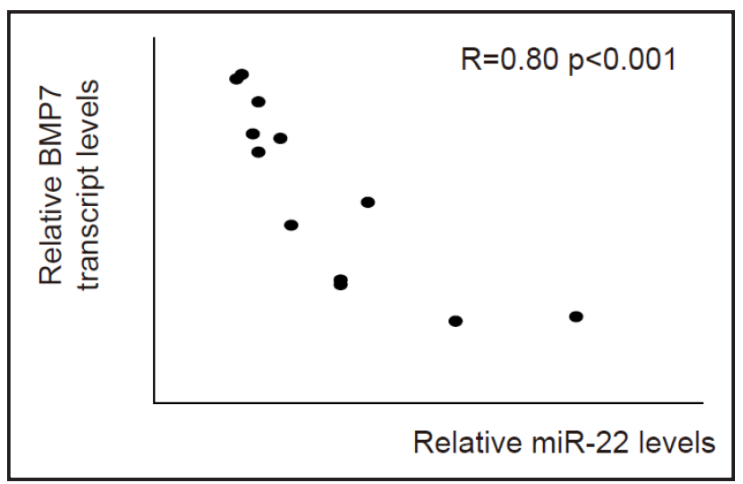



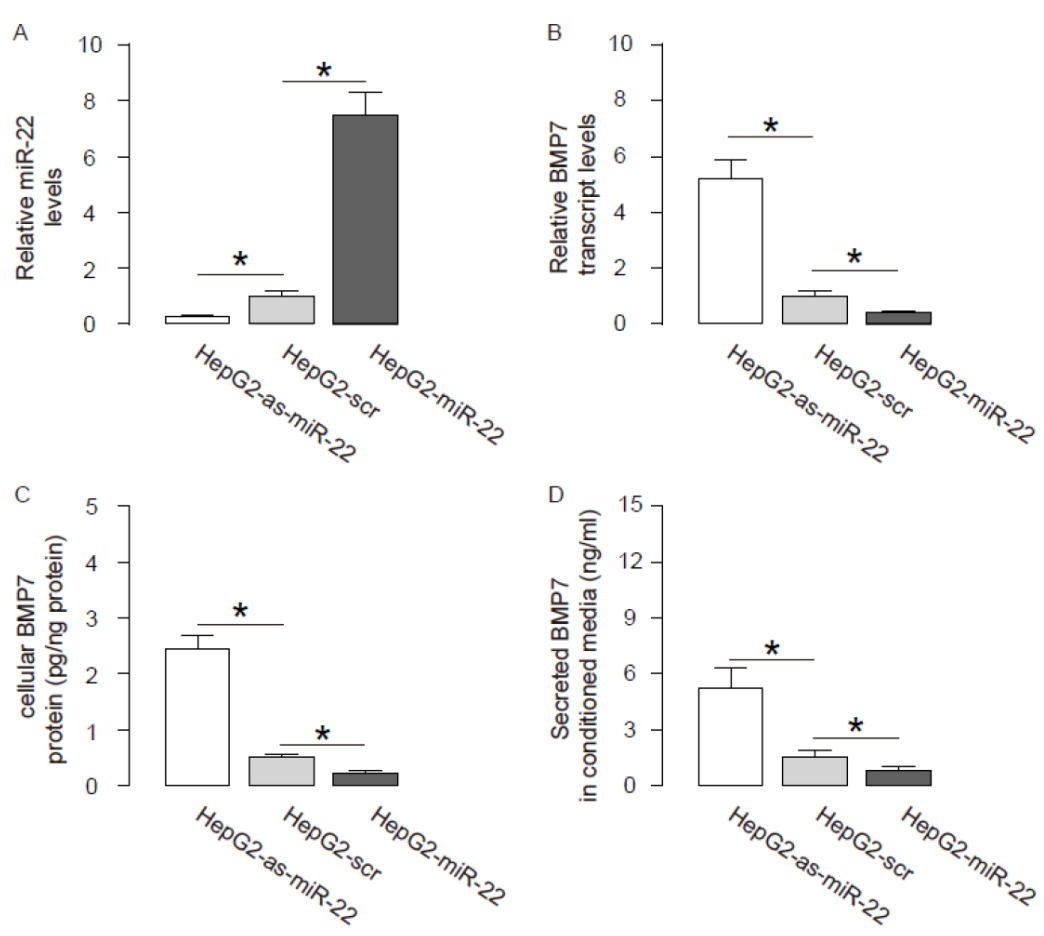

Fig. 2. MiR-22 suppressed BMP7 expression in hepatocytes. We overexpressed miR-22 or as-miR-22 or control scrambled sequence (scr) in a hepatocyte cell line, HepG2. (A) Modulation of miR-22 levels in HepG2 cells was confirmed by RT-qPCR. (B-D) The expression of BMP7 in miR-22-overexpressing HepG2 cells was significantly decreased, while the expression of BMP7 in miR-22-depleted HepG2 cells was significantly increased, by RT-qPCR (B), and by ELISA on either cellular protein (C) or secreted protein (D). *: p<0.05. $n=10$. Statistics: one-way ANOVA with a Bonferoni correction.

Fig. 3. MiR-22 targets 3'UTR of BMP7 to inhibit its expression. (A) Bioinformatics analyses of BMP7 target sequence show that the miR-22 binding sites in the BMP7 mRNA sequence 3'UTR ranged from 129th base site to 159th base site. (B) HepG2miR-22, HepG2-scr (control) and HepG2-as-miR-22 cells were transfected with $1 \mu \mathrm{g}$ of BMP73'UTR luciferase-reporter plasmid. The luciferase activities in these cells were then evaluated. *: $\mathrm{p}<0.05 . \mathrm{n}=10$. Statistics: oneway ANOVA with a Bonferoni correction.
A

$\mathrm{B}$

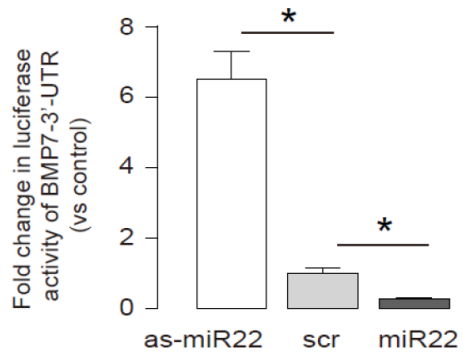

knockdown of miR-22 in liver increased BMP7 mRNA levels by about 2.8 folds (Fig. 4C), but increased BMP7 protein levels by about 6.3 folds (Fig. 4D).

At sacrifice, the features of cirrhosis were analyzed in mice that received either asmiR-22 or control scr viruses. The fibrotic area was evaluated after Sirius red staining, showing that knockdown of miR-22 by as-miR-22 significantly decreased the percentage of 
Fig. 4. Efficient inhibition of miR-22 in the liver. (A) In order to evaluate the inhibitory effect of miR-22 on BMP7 and cirrhosis in vivo, we used a well-established $\mathrm{CCl}_{4}$-induced cirrhosis animal model. Mice were i.p. injected of $\mathrm{CCl}_{4}$ twice per week for 8 weeks. During this period, 0.3 $\mathrm{g} / \mathrm{L}$ phenobarbital was provided in drinking water to enhance $\mathrm{CCl}_{4}$ hepatotoxicity. Afterwards, the mice received hepatic infusion with AAV that carry as-miR-22, or scr as a control, through common bile duct, and were kept for another 4 weeks before analyses. (B) Representative image for GFP expression in the liver after viral delivery. (C) RT-qPCR for miR-22 and BMP7 in the

A

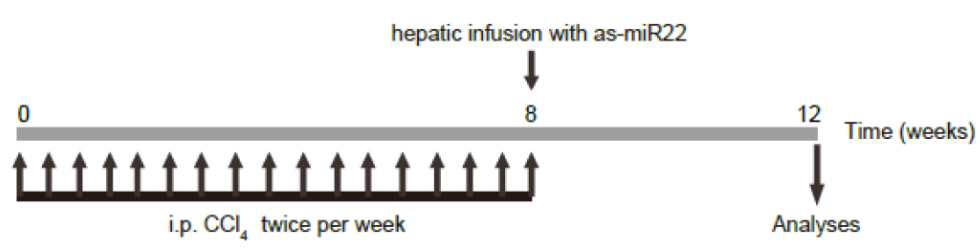

B
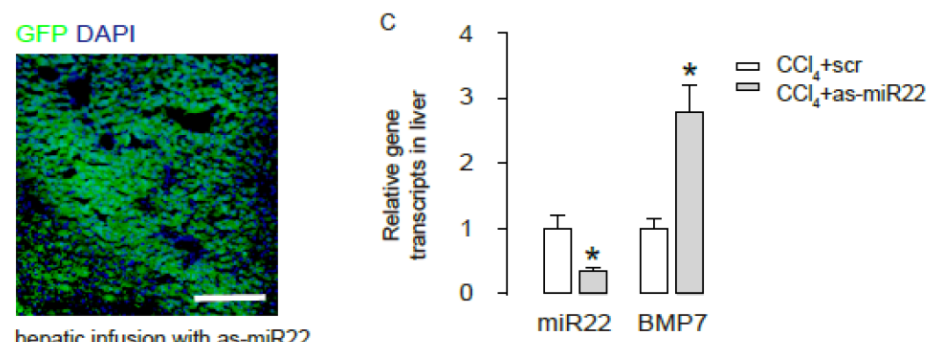

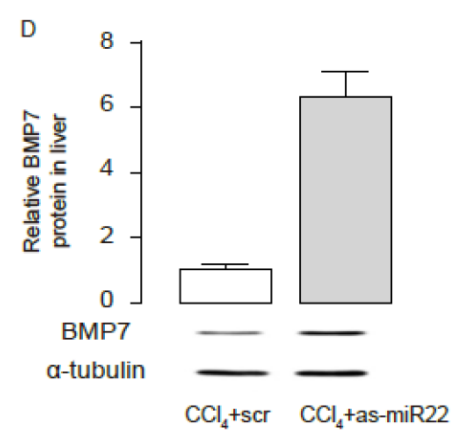

liver. (D) Western blot for BMP7 in the liver. *: $\mathrm{p}<0.05 . \mathrm{n}=10$. Statistics: one-way ANOVA with a Bonferoni correction. Scale bar is $100 \mu \mathrm{m}$.

the fibrotic area (Fig. 5A). Portal hypertension and sodium metabolism were also assessed, showing that knockdown of miR-22 by as-miR-22 significantly decreased the portal pressure (Fig. 5B) and significantly improved sodium balance (Fig. 5C), probably through an increased sodium excretion (Fig. 5D). These data suggest that as-miR-22 significantly alleviated the features of cirrhosis induced by $\mathrm{CCl}_{4}$. This model is thus summarized in a schematic (Fig. 6).

\section{Discussion}

Recently, we have shown that that mesenchymal stem cells produce high levels of BMP7, which antagonizes TGF $\beta 1$-induced development of cirrhosis in mice [20]. Since BMP7 plays a pivotal role in suppressing the development of cirrhosis, here we studied its regulation by miRNAs.

miRNAs are frequently dysregulated in cancer and are associated with cancer development and progression [26-28]. Recent findings have implicated the involvement of miRNAs in the HCV infection and development of cirrhosis. Although the role of miR-22 has not been studied in cirrhosis pathogenesis, it was recently implied in a study on kidney in which the authors used a unilateral ureteral obstruction (UUO) model of kidney fibrosis to elucidate direct regulation of BMP7 by miR-22 binding to the 3'-UTR on mRNA [38]. Importantly, mice with targeted deletion of miR-22 exhibited attenuated renal fibrosis in the UUO model [38]. Primary renal fibroblasts in miR-22-deficient UUO mice demonstrate significant increases in BMP7 expression and presented increased resistance to UUO- 


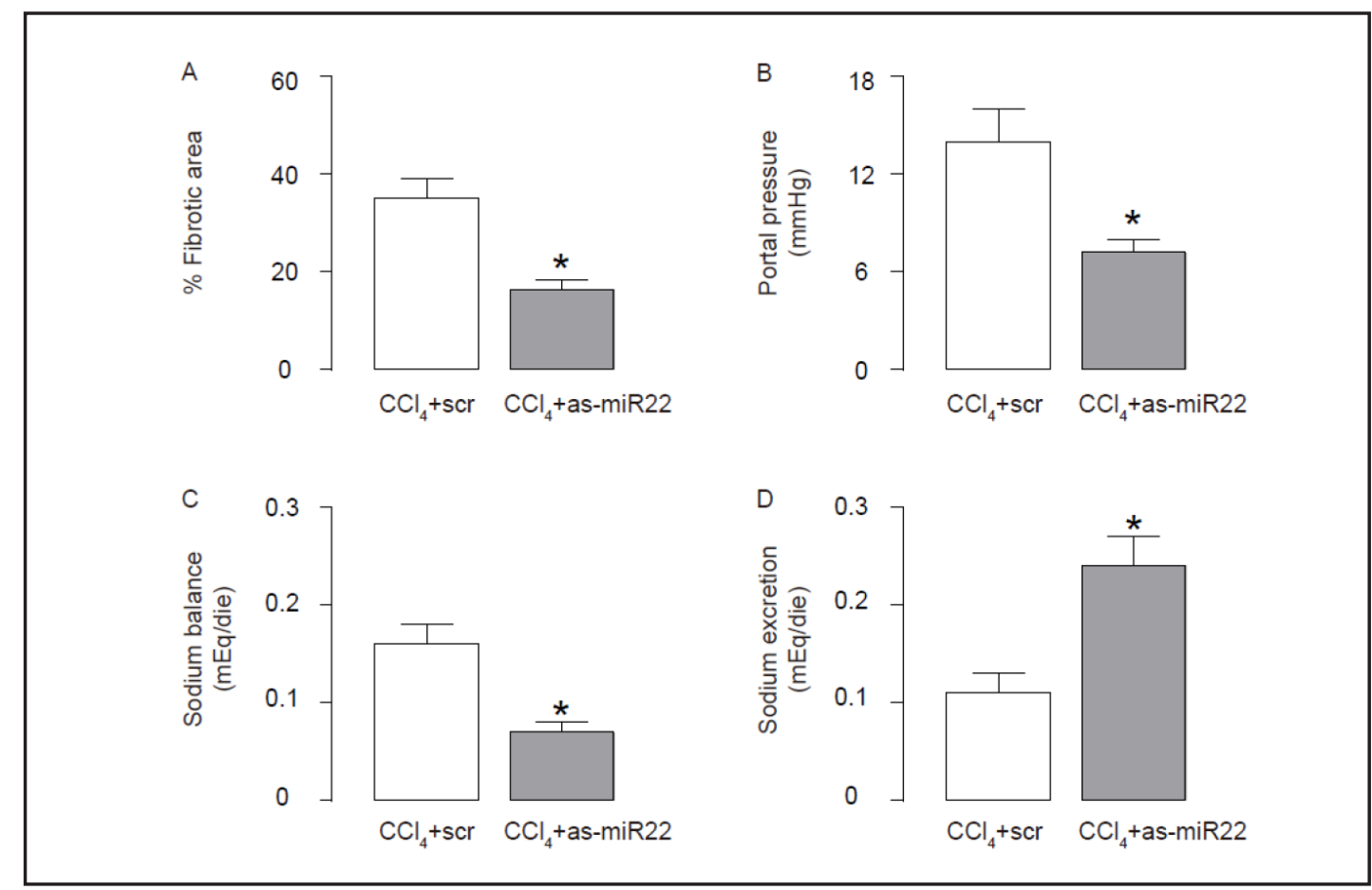

Fig. 5. As-miR-22 significantly alleviated the features of cirrhosis induced by $\mathrm{CCl}_{4}$. (A) The fibrotic area at sacrifice was evaluated after Sirius red staining, shown by the percentage of the fibrotic area. (B) Portal pressure. (C) Sodium balance. (D) Sodium excretion. *: p<0.05. $n=10$. Statistics: one-way ANOVA with a Bonferoni correction.

Fig. 6. Schematic of the model. MiR-22 inhibits BMP7 expression in hepatocytes, through directly binding and inhibition through 3'-UTR of BMP7 mRNA, which promotes the development of cirrhosis.

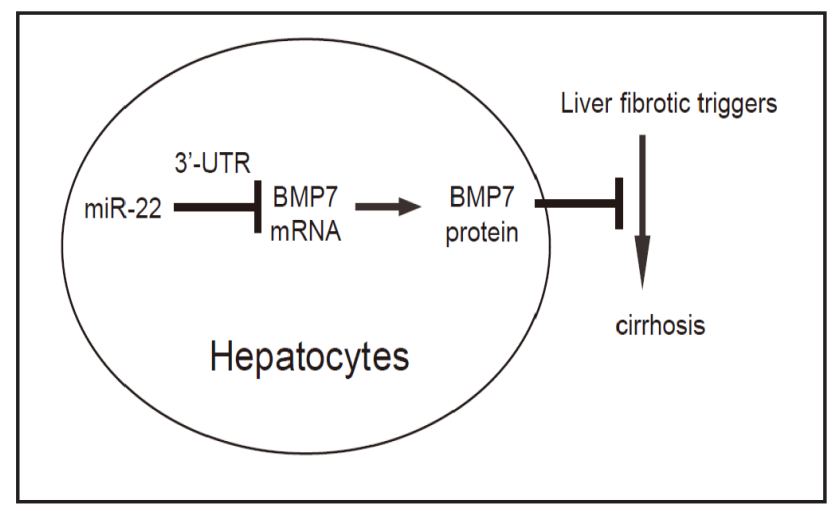

mediated fibrosis [38]. This study inspired us to do an examination on liver fibrosis, since BMP7 is known to play a similar anti-fibrotic role in both kidney and liver.

We found that the levels of miR-22 and BMP7 in the liver biopsies strongly and inversely correlated. This result is pretty important, since it demonstrates the presence of miR-22 in fibrotic liver and a possible role of miR-22 in regulating BMP7. To confirm it, we modified miR-22 levels in hepatocytes in vitro. We found that the modification of miR-22 indeed altered BMP7 level. These data suggest that the regulation of BMP7 by miR-22 in hepatocytes may be similar to those in renal cells [38]. Since miRNAs normally target 3'-UTR of mRNA of a gene to inhibit its expression, we analyzed its regulation by miRNAs in the current study. Indeed, our data demonstrate a strong regulatory effect of miR-22 on BMP7 mRNA, similar to what had been found in renal fibrosis model [38], in which the authors found that BMP7 were significantly elevated in the kidneys of the miR-22-knock-out mouse. Importantly, in this study, mice with targeted deletion of miR-22 exhibited attenuated renal fibrosis in the UUO model. Consistent with these in vivo observations, primary renal fibroblast isolated 


\section{Cellular Physiology Cell Physiol Biochem 2015;36:1026-1036 \begin{tabular}{l|l} 
DOI: 10.1159/000430276 & (c) 2015 S. Karger AG, Basel
\end{tabular} and Biochemistry Published online: June 16, 2015

from miR-22-deficient UUO mice demonstrated a significant increase in BMP7 expression and their downstream targets.

Then we used a loss-of-function experiment to examine the regulation of BMP7 by miR-22 in vivo in a cirrhosis model. Compared with genetically modified mouse models for cirrhosis, a $\mathrm{CCl}_{4}$-induced model has some advantages in that it best resembles human liver fibrotic diseases [5-10]. We administrated as-miR-22 through common bile duct, rather than through circulation. This method has a lot of advantages, like no first by-pass effect, induction of localized infection without affecting cells from other organs and tissues, less off-target effects, etc. Expression of antisense of miR-22 significantly attenuated the levels of liver fibrosis, portal hypertension and sodium retention caused by $\mathrm{CCl}_{4}$, possibly through upregulation of BMP7. Our data that show the effects of as-miR-22 on BMP are more pronounced at protein level than at mRNA level are consistent with the findings that miR-22 targets 3'-UTR of mRNA of BMP7, in which the regulation is more like at protein translation. The relative modest effects on mRNA of BMP7 may be feedback of this regulation. However, our data do not exclude the possibility that miR-22 could be targeting in addition to BMP7 that may contribute to the cirrhosis effect.

Moreover, several other lines have been checked to exclude a possibility of cell-line dependence. Together, these data suggest that inhibition of miR-22 may be a potentially promising therapeutic approach for treating and preventing cirrhosis.

\section{Acknowledge}

This work was financially supported by Wang Baoen Foundation for Liver Fibrosis Research, NO 434510Z0A10 and National Natural Science Foundation of China, NO 81371799.

\section{Disclosure Statement}

The authors have declared that no competing interests exist.

\section{Reference}

1 Hirschfield GM, Gershwin ME: The immunobiology and pathophysiology of primary biliary cirrhosis. Annu Rev Pathol 2013;8:303-330.

2 Invernizzi P, Selmi C, Gershwin ME: Update on primary biliary cirrhosis. Dig Liver Dis 2010;42:401-408.

3 Selmi C, Lleo A, Pasini S, Zuin M, Gershwin ME: Innate immunity and primary biliary cirrhosis. Curr Mol Med 2009;9:45-51.

4 Tangkijvanich P, Yee HF, Jr: Cirrhosis--can we reverse hepatic fibrosis? Eur J SurgS uppl 2002:100-112.

5 Selmi C, Meda F, Kasangian A, Invernizzi P, Tian Z, Lian Z, Podda M, Gershwin ME: Experimental evidence on the immunopathogenesis of primary biliary cirrhosis. Cell Mol Immunol 2010;7:1-10.

6 Chuang YH, Ridgway WM, Ueno Y, Gershwin ME: Animal models of primary biliary cirrhosis. Clin Liver Dis 2008;12:333-347; ix.

7 Concepcion AR, Medina JF: Approaches to the pathogenesis of primary biliary cirrhosis through animal models. Clin Res Hepatol Gastroenterol 2012;36:21-28.

8 Tsuneyama K, Moritoki Y, Kikuchi K, Nakanuma Y: Pathological features of new animal models for primary biliary cirrhosis. Int J Hepatol 2012;2012:403954.

9 Leung PS, Yang GX, Dhirapong A, Tsuneyama K, Ridgway WM, Gershwin ME: Animal models of primary biliary cirrhosis: Materials and methods. Methods Mol Biol 2012;900:291-316.

10 Wang J, Yang GX, Tsuneyama K, Gershwin ME, Ridgway WM, Leung PS: Animal models of primary biliary cirrhosis. Semin Liver Dis 2014;34:285-296. 


\section{Cellular Physiology Cell Physiol Biochem 2015;36:1026-1036 \begin{tabular}{l|l|l} 
DOI: 10.1159/000430276 & (C)15 S. Karger AG, Basel
\end{tabular} and Biochemistry Published online: June 16, 2015 \\ Ji et al.: MiR-22 Suppresses Cirrhosis}

11 Baghy K, Iozzo RV, Kovalszky I: Decorin-tgfbeta axis in hepatic fibrosis and cirrhosis. J Histochem Cytochem 2012;60:262-268.

12 Massague J: Tgfbeta signalling in context. Nat Rev Mol Cell Biol 2012;13:616-630.

13 Lan HY, Chung AC: Transforming growth factor-beta and smads. Contrib Nephrol 2011;170:75-82.

14 Xiao X, Gaffar I, Guo P, Wiersch J, Fischbach S, Peirish L, Song Z, El-Gohary Y, Prasadan K, Shiota C, Gittes GK: M2 macrophages promote beta-cell proliferation by up-regulation of smad7. Proc Natl Acad Sci U S A 2014;111:E1211-1220.

15 Liu G, Cheng J, Guan G, Jia Z: Renal lymph circulation blockage alters the epithelial cell phenotype and tubular integrity: Role of distinct regulation of bmp7 and tgf-beta/smads signaling pathway. Int Urol Nephrol 2014;46:1239-1246.

16 Khan I, Agarwal P, Thangjam GS, Radhesh R, Rao SG, Kondaiah P: Role of tgf-beta and bmp7 in the pathogenesis of oral submucous fibrosis. Growth Factors 2011;29:119-127.

17 Buijs JT, Henriquez NV, van Overveld PG, van der Horst G, ten Dijke P, van der Pluijm G: Tgf-beta and bmp7 interactions in tumour progression and bone metastasis. Clin Exp Metastasis 2007;24:609-617.

18 Wang S, Hirschberg R: Bmp7 antagonizes tgf-beta -dependent fibrogenesis in mesangial cells. Am J Physiol Renal Physiol 2003;284:F1006-1013.

19 Shen B, Liu X, Fan Y, Qiu J: Macrophages regulate renal fibrosis through modulating tgfbeta superfamily signaling. Inflammation 2014;37:2076-2084.

20 Li B, Shao Q Ji D, Li F, Chen G: Mesenchymal stem cells mitigate cirrhosis through bmp7. Cell Physiol Biochem 2015;35:433-440.

21 Wang S, Hyun J, Youn B, Jung Y: Hedgehog signaling regulates the repair response in mouse liver damaged by irradiation. Radiat Res 2013;179:69-75.

22 Zeisberg M, Yang C, Martino M, Duncan MB, Rieder F, Tanjore H, Kalluri R: Fibroblasts derive from hepatocytes in liver fibrosis via epithelial to mesenchymal transition. J Biol Chem 2007;282:23337-23347.

23 Kinoshita K, Iimuro Y, Otogawa K, Saika S, Inagaki Y, Nakajima Y, Kawada N, Fujimoto J, Friedman SL, Ikeda K: Adenovirus-mediated expression of bmp-7 suppresses the development of liver fibrosis in rats. Gut 2007;56:706-714.

24 Sugimoto H, Yang C, LeBleu VS, Soubasakos MA, Giraldo M, Zeisberg M, Kalluri R: Bmp-7 functions as a novel hormone to facilitate liver regeneration. FASEB J 2007;21:256-264.

25 Jones CN, Tuleuova N, Lee JY, Ramanculov E, Reddi AH, Zern MA, Revzin A: Cultivating hepatocytes on printed arrays of hgf and bmp7 to characterize protective effects of these growth factors during in vitro alcohol injury. Biomaterials 2010;31:5936-5944.

26 O'Loughlin AJ, Woffindale CA, Wood MJ: Exosomes and the emerging field of exosome-based gene therapy. Curr Gene Ther 2012;12:262-274.

27 Pant S, Hilton H, Burczynski ME: The multifaceted exosome: Biogenesis, role in normal and aberrant cellular function, and frontiers for pharmacological and biomarker opportunities. Biochem Pharmacol 2012;83:1484-1494.

28 Bobrie A, Colombo M, Raposo G, Thery C: Exosome secretion: Molecular mechanisms and roles in immune responses. Traffic 2011;12:1659-1668.

29 Zhou WC, Zhang QB, Qiao L: Pathogenesis of liver cirrhosis. World J Gastroenterol 2014;20:7312-7324.

30 Xin X, Zhang Y, Liu X, Xin H, Cao Y, Geng M: Microrna in hepatic fibrosis and cirrhosis. Front Biosci 2014;19:1418-1424.

31 Wojcicka A, Swierniak M, Kornasiewicz O, Gierlikowski W, Maciag M, Kolanowska M, Kotlarek M, Gornicka B, Koperski L, Niewinski G, Krawczyk M, Jazdzewski K: Next generation sequencing reveals microrna isoforms in liver cirrhosis and hepatocellular carcinoma. Int J Biochem Cell Biol 2014;53:208-217.

32 Vuppalanchi R, Liang T, Goswami CP, Nalamasu R, Li L, Jones D, Wei R, Liu W, Sarasani V, Janga SC, Chalasani $\mathrm{N}$ : Relationship between differential hepatic microrna expression and decreased hepatic cytochrome p450 3a activity in cirrhosis. PLoS One 2013;8:e74471.

33 Chen YJ, Zhu JM, Wu H, Fan J, Zhou J, Hu J, Yu Q Liu TT, Yang L, Wu CL, Guo XL, Huang XW, Shen XZ: Circulating micrornas as a fingerprint for liver cirrhosis. PLoS One 2013;8:e66577.

34 Waidmann O, Koberle V, Brunner F, Zeuzem S, Piiper A, Kronenberger B: Serum microrna-122 predicts survival in patients with liver cirrhosis. PLoS One 2012; 7:e45652. 


\section{Cellular Physiology Cell Physiol Biochem 2015;36:1026-1036 \begin{tabular}{ll|l} 
and Biochemistry $\begin{array}{l}\text { DOI: 10.1159/000430276 } \\
\text { Published online: June 16, } 2015\end{array}$ & $\begin{array}{l}\text { O) 2015 S. Karger AG, Basel } \\
\text { www.karger.com/cpb }\end{array}$ \\
\cline { 2 - 3 }
\end{tabular} \\ Ji et al.: MiR-22 Suppresses Cirrhosis}

35 Padgett KA, Lan RY, Leung PC, Lleo A, Dawson K, Pfeiff J, Mao TK, Coppel RL, Ansari AA, Gershwin ME: Primary biliary cirrhosis is associated with altered hepatic microrna expression. J Autoimmun 2009;32:246-253.

36 Feng YY, Xu XQ, Ji CB, Shi CM, Guo XR, Fu JF: Aberrant hepatic microrna expression in nonalcoholic fatty liver disease. Cell Physiol Biochem 2014;34:1983-1997.

37 Gong XH, Chen C, Hou P, Zhu SC, Wu CQ Song CL, Ni W, Hu JF, Yao DK, Kang JH, Zhu L: Overexpression of mir-126 inhibits the activation and migration of hscs through targeting crk. Cell Physiol Biochem 2014;33:97-106.

38 Long J, Badal SS, Wang Y, Chang BH, Rodriguez A, Danesh FR: Microrna-22 is a master regulator of bone morphogenetic protein-7/6 homeostasis in the kidney. J Biol Chem 2013;288:36202-36214.

39 Iliopoulos D, Malizos KN, Oikonomou P, Tsezou A: Integrative microrna and proteomic approaches identify novel osteoarthritis genes and their collaborative metabolic and inflammatory networks. PLoS One 2008;3:e3740.

40 Knowles BB, Howe CC, Aden DP: Human hepatocellular carcinoma cell lines secrete the major plasma proteins and hepatitis b surface antigen. Science 1980;209:497-499.

41 Khan IF, Hirata RK, Russell DW: Aav-mediated gene targeting methods for human cells. Nat Protoc 2011;6:482-501.

42 Hajitou A, Rangel R, Trepel M, Soghomonyan S, Gelovani JG, Alauddin MM, Pasqualini R, Arap W: Design and construction of targeted aavp vectors for mammalian cell transduction. Nat Protoc 2007;2:523-531.

43 Grieger JC, Choi VW, Samulski RJ: Production and characterization of adeno-associated viral vectors. Nat Protoc 2006;1:1412-1428.

44 Jiang X, Ren Y, Williford JM, Li Z, Mao HQ: Liver-targeted gene delivery through retrograde intrabiliary infusion. Methods Mol Biol 2013;948:275-284.

45 Xiao X, Guo P, Prasadan K, Shiota C, Peirish L, Fischbach S, Song Z, Gaffar I, Wiersch J, El-Gohary Y, Husain SZ, Gittes GK: Pancreatic cell tracing, lineage tagging and targeted genetic manipulations in multiple cell types using pancreatic ductal infusion of adeno-associated viral vectors and/or cell-tagging dyes. Nat Protoc 2014;9:2719-2724.

46 Thomas M, Rieger JK, Kandel BA, Klein K, Zanger UM: Targeting nuclear receptors with lentivirus-delivered small rnas in primary human hepatocytes. Cell Physiol Biochem 2014;33:2003-2013. 